\title{
Extremely high volatiles of petit-spot
}

\author{
NAOTO HIRANO ${ }^{1,2}$, YUKI KATSURAGI ${ }^{2}$, TAKAYUKI \\ USHIKUBO $^{3}$, KENJI SHIMIZU ${ }^{3}$ \\ ${ }^{1}$ Cnter for NE-Asian Studies, Tohoku Univ., 41 Kawauchi, \\ Aoba, Sendai 920-8576, Japan. nhirano@tohoku.ac.jp \\ ${ }^{2}$ Faculty of Science, Tohoku Univ., 6-3 Aramaki-Aoba, Aoba, \\ Sendaim 980-8578, Japan.
}

${ }^{3}$ Kochi Institute for Core Sample Research, JAMSTEC, 200

Monobe Otsu, Nankoku, 783-8502, Japan.

Submarine petit-spot volcanoes induced by lithospheric flexure were first reported on the subducting northwestern Pacific Plate ${ }^{1}$ and the erupted lavas are either completely alkaline or strongly alkaline with extremely high vesicularity; examples of such volcanoes have recently been discovered on the plates subducting along the Chile ${ }^{2}$, Sunda ${ }^{3}$ and Mariana ${ }^{4}$ trenches. High levels of $\mathrm{CO}_{2}$ in the magma prior to degassing ${ }^{6}$ cause the high vesicularity observed in spite of the eruptions occuring under high submarine hydrostatic pressures. As a carbonatite melt has been proposed as the key material to explain the electrical conductivity of the oceanic asthenosphere ${ }^{7}$, the extremely high $\mathrm{CO}_{2}$ contents of petit-spot volcanoes raises the possibility that $\mathrm{CO}_{2}$ affects the source components and their melting. We report the volatile contents of carbon, water and halogens in the quenched glass rinds and melt inclusions to recognize the mantle source and magma ascension process in the subduction of an old Pacific plate.

Extremely high $\mathrm{CO}_{2}$ contents (up to $2,000 \mathrm{ppm}$ ) were strongly correlated with the $\mathrm{SiO}_{2}$ contents in the volcanic glasses even though these glasses were sampled from several volcanoes that were independently distributed in terms of their eruptive ages and locations on the NW Pacific Plate. The higher $\mathrm{CO}_{2}$ contents of the olivine-hosted melt inclusions indicate the magma compositions prior to exsolution. The ratios of water and halogens, on the other hand, clearly indicate an "enriched mantle" component, as do the data represented by the $\mathrm{Nd}$ and $\mathrm{Pb}$ isotopic compositions. ${ }^{8,9}$ Our data provide a new understanding of the source components of the asthenosphere below the NW Pacific Plate prior to subduction.

\section{Refernces:}

${ }^{1}$ Hirano et al. (2006) Science 313, 1426-1428.

${ }^{2}$ Hirano et al. (2013) Geochem. J. 47, 249-257.

${ }^{3}$ Taneja et al. (2015) Gondwana Res. 28, 391-406.

${ }^{4}$ Hirano et al. (2019) Deep Sea Res. I 154, 103142.

${ }^{5}$ Dixon \& Stolper (1995) J. Petrol. 36, 1633-1646.

${ }^{6}$ Okumura \& Hirano (2013) Geology 41, 1167-1170.

${ }^{7}$ Sifré et al. (2014) Nature 509, 81-85.

${ }^{8}$ Shimizu et al. (2019) Chem. Geol. 522, 283-294.

${ }^{9}$ Machida et al. (2015) EPSL 426, 267-279. 